\title{
A ADAPTAÇÃO DA IMAGEM EM FACE DE INTERLOCUTORES DISTINTOS: O USO DE MECANISMOS DE EFEITO CORTÊS
}

\author{
IMAGE ADAPTATION IN FACE OF DIFFERENT \\ INTERLOCUTORS: THE USE OF MECHANISMS OF \\ POLITENESS EFFECT
}

Gabriela Colbeich da Silva*

Resumo: Neste trabalho, propomo-nos a examinar duas interações presentes na propaganda Surpresa em uma loja VIVO, que faz parte da ação \#TAMOCONECTADO de uma operadora brasileira de telefonia móvel e fixa, internet banda larga e TV por assinatura por meio das noções de imagem pública e dos mecanismos de (de)cortesia advindas da Pragmática (BROWN e LEVINSON, 1978) e da Sociologia (GOFFMAN, 1959). Nosso objetivo geral é tentar compreender o que leva um dos clientes da VIVO, quando em presença de Luiz Felipe Scolari - atual técnico da Seleção Brasileira -, a modificar sua segunda resposta a um mesmo questionamento acerca de seu ponto de vista sobre a Seleção Brasileira na Copa do Mundo de Futebol 2014. Para tanto, analisaremos como o uso de mecanismos atenuadores pode provocar efeitos que esboçam uma imagem cortês através de uma metodologia baseada no paradigma indiciário (GINZBURG, 1989).

Palavras-chave: imagem, cortesia, atenuadores.

Aвstract: In this essay, we intend to examine two interactions present in the advertisement Surpresa em uma loja VIVO ("Surprise in a VIVO store"), which forms part of the campaign \#TAMOCONECTADO (“\#WEARECONNECTED”) by a Brazilian Internet telephony and cable television service provider, through the notions of public image and the mechanisms of (im)politeness derived from Pragmatics (BROWN and LEVINSON, 1978) and Sociology (GOFFMAN, 1959). Our general objective is to try to comprehend what causes one of VIVO's client, when in the presence of Luiz Felipe Scolari - current head coach of Brazil's soccer team -, to modify his second answer to a same question about his point of view concerning Brazil's soccer team at the 2014 World Cup. For this purpose, we will analyze how the use of softening mechanisms

\footnotetext{
"Mestre em Estudos Linguísticos. Universidade Federal de Santa Maria. Email: gabi.colbeich@gmail.com
} 
can provoke effects that sketch a polite image through a methodology based on the 'indiciary paradigm' (GINZBURG, 1989).

KEYWORDs: image, politeness, softener.

Pontos DE PARTIDA: CONSIDERAÇÕES INICIAIS

Interagir por meio de uma língua, seja na modalidade oral ou escrita, implica a construção e a percepção de uma imagem. Não é preciso que nos descrevamos, nosso próprio modo de "dizer" é suficiente para produzir uma representação de nossa pessoa e essa imagem pode facilitar ou mesmo condicionar a interação ${ }^{1}$ (AMOSSY, 2005).

Essa apresentação não se refere a uma técnica apreendida ou a um artifício: ela se efetua, com frequência, à revelia dos parceiros, nas trocas verbais mais corriqueiras e mais pessoais (AMOSSY, 2005). Dessa forma, a relevância e o grau de persuasão de nossas interações não dependem somente daquilo que dizemos, mas, também, da imagem que esboçamos, da impressão que provocamos nos demais a partir do modo como dizemos.

A imagem que construímos no e pelo discurso pode ser compreendida desde distintos campos teóricos, tais como a Antropologia, a Argumentação, a Linguística da Enunciação, a Pragmática, a Retórica Aristotélica, a Sociologia, etc. Neste trabalho, vamos nos restringir à análise da imagem

\footnotetext{
${ }^{1}$ Para os fins deste trabalho, consideraremos como interação "a influência recíproca dos indivíduos sobre as ações uns dos outros" (GOFFMAN, 1959, p. 28). Contudo, ao contrário daquilo que Goffman (1959) defende, acreditamos que essa influência não se limita às ações face a face, ou seja, não ocorre somente quando os interlocutores estão em presença física imediata.
}

desde duas dessas perspectivas: Pragmática e Sociologia.

Por intermédio deste trabalho, propomo-nos a examinar duas interações presentes na propaganda Surpresa em uma loja VIVO, que faz parte da ação\#TAMOCONECTADO de uma operadora brasileira de telefonia móvel e fixa, internet banda larga e TV por assinatura. Nosso objetivo geral é tentar compreender o que leva um dos clientes da VIVO, quando em presença de Luiz Felipe Scolari - atual técnico da Seleção Brasileira -, a modificar sua segunda resposta a um mesmo questionamento acerca de seu ponto de vista sobre a Seleção Brasileira na Copa do Mundo de Futebol 2014.

Para tanto, verificaremos quais são os mecanismos linguísticos utilizados nas interações deste cliente (doravante, L2) com $o$ atendente da VIVO (doravante, LI) e com Luiz Felipe Scolari (doravante, L3) e de que forma tais mecanismos podem auxiliar a traçar distintas imagens sociais de L2 em cada interação.

\section{BASES DE RACIOCÍNIO E INTERPRETAÇÃO: REFERENCIAL TEÓRICO}

A linguagem está relacionada ao seu contexto de utilização: tempo, espaço e pessoa(s). Afeta, no mínimo, a um locutor e a um interlocutor que não somente intercambiam informações, mas que interagem, buscando alcançar certos objetivos por meio 
dos mecanismos que a língua lhes dispõe. Vejamos alguns destes aspectos.

\section{Pragmática e imagem pública}

No início, as reflexões pragmáticas não estabeleciam nenhuma relação com as reflexões linguísticas, já que aquelas se originaram de uma série de reflexões conhecidas como Filosofia da Linguagem. Segundo Bravo (2004), na medida em que a Pragmática se fortalece como parte da Linguística, começa a se verificar de maneira premente a necessidade de conciliar os estudos empíricos, ou seja, os que se ocupam do uso de uma língua em seu próprio contexto, com os teóricos, que deveriam dar conta de condições gerais para o uso das línguas. Esta desconexão, baseada na relativa "juventud lingüística de la pragmática” (BRAVO, 2004, p.7) e na consequente desconfiança dos primeiros linguistas sobre o contexto do locutor, reflete-se de forma crucial quando se trata de fenômenos cuja etiologia é sócio pragmática, como é o caso da Cortesia ${ }^{2}$.

Um dos conceitos basilares da Pragmática é a noção de locutor. Esse é a pessoa que produz intencionalmente uma expressão linguística em uma situação, seja na modalidade oral ou escrita, não um mero codificador ou transmissor mecânico de informações, mas um sujeito real, psicobiológico, com seus conhecimentos, crenças e

\footnotetext{
${ }^{2}$ Em Lingüística, entende-se por Cortesia o conjunto de estratégias linguísticas (verbais ou não verbais) destinadas a evitar ou diminuir as tensões que aparecem quando um locutor enfrenta um 'conflito' produzido entre seus próprios objetivos e os de seu(s) interlocutor(es) (CVC Diccionario de Términos Clave de ELE).
}

atitudes, capaz de estabelecer toda uma rede de diferentes relações com seu entorno (VIDAL, 1999).

Para Bravo (2004), a Pragmática constitui uma perspectiva funcionalista da linguagem, visto que a analisa desde o ponto de vista do usuário. Dessa forma, orienta-se à consideração das condições sociais que possibilitam aos interlocutores o acesso e a aplicação de recursos da linguagem. Vidal afirma que

[...] la adopción de una perspectiva pragmática ha permitido arrojar nueva luz sobre diversos fenómenos, $y$ así se han propuesto enfoques esclarecedores en muchas áreas, como la referencia nominal y temporal, la deixis, el orden de palabrasy la estructura informativa, o los marcadores discursivos. En estos ámbitos se ha puesto de relieve la necesidad de tomar en cuenta a los participantes en la comunicación y su entorno para poder ofrecer una caracterización completa de los fenómenos ${ }^{3}$ (VIDAL, s/d, p.I).

Se o enfoque pragmático torna-se necessário para explicar questões que pareciam exclusivamente gramaticais, não seria incomum que também se tornasse imprescindível em muitos aspectos em que é essencial recorrer a elementos que, sendo externos

\footnotetext{
${ }^{3}$ [...] a adoção de uma perspectiva pragmática permitiu lançar um novo olhar sobre diferentes fenômenos e, dessa maneira, propuseram-se enfoques esclarecedores em muitas áreas como as referências nominal e temporal, a dêixis, a ordem das palavras e a estrutura informativa ou os marcadores discursivos. Nestes âmbitos, a necessidade de considerar os participantes da comunicação e seu entorno tornaram-se indispensáveis para que se possa oferecer uma caracterização completa dos fenômenos (tradução nossa) (VIDAL, s/d, p.1).
} 
ao sistema de uma língua, direcionam o uso que fazemos dela, tais como os interlocutores, o contexto, o conhecimento de mundo e a intenção comunicativa (VIDAL, 1999). Investigaremos a noção de imagem, neste trabalho, que pode vincular-se a um desses elementos externos, a intenção.

Os indivíduos, em sua maioria, ambicionam construir uma imagem social de si e esperam que esta seja respeitada em suas trocas comunicativas. Como vivemos em sociedade, aspiramos que essa imagem seja aceita e considerada pelo grupo ao que pertencemos. Para tanto, necessitamos conhecer aquilo que caracteriza a comunicação entre os membros de nosso grupo e dominar as estratégias (verbais ou não verbais) que podem funcionar como ferramentas para alcançar esse propósito social de satisfação da imagem, o que Goffman (1967) denominou atividades de imagem (face work).

Sociologia E A REPRESENTAÇ̃̃o E O “EU” GOFFMAN (1967)

A função da imagem de si e do outro construída no discurso se manifesta plenamente na perspectiva interacional. Dizer que os interlocutores interagem é pressupor que a imagem construída no e pelo discurso participa da influência que exercem, mutuamente, um sobre o outro.

A produção de uma imagem de si nas interações começou a receber maior atenção a partir dos trabalhos do sociólogo canadense Erving Goffman, cujas pesquisas sobre a representação de si e os rituais de interação exerceram profunda influência na análise das conversações (AMOSSY, 2005). O sociólogo mostra que toda interação social exige que os atores forneçam, por seu comportamento voluntário ou involuntário, certa impressão de si mesmos que contribui para influenciar seus parceiros de modo desejado.

Goffman (1959) divide implicitamente o indivíduo em dois papéis fundamentais cujas propriedades são de ordens diferentes. O primeiro deles é o de ator que considera como um "atormentado fabricante de impressões envolvido na tarefa demasiado humana de encenar uma representação" (GOFFMAN, 1959, p. 270). O segundo é o de personagem enquanto uma figura "tipicamente [...] admirável, cujo espírito, força e outras excelentes qualidades a representação tinha por finalidade evocar" (GOFFMAN, 1959, p.270).

No que se refere à personagem, o sociólogo afirma que, no palco, o indivíduo no papel de personagem tenta induzir, efetivamente, os outros a terem a seu respeito uma espécie de imagem, geralmente digna de crédito, uma personalidade encenada. Embora esta imagem seja creditada/atribuída ao indivíduo e acabe lhe conferindo uma personalidade, esta não se origina do seu possuidor, mas da cena de sua ação em sua integralidade. Uma "cena corretamente representada conduz a plateia a atribuir uma personalidade ao personagem representado, mas esta atribuição - este "eu" - é um 'produto' de uma cena que se verificou, e não uma 'causa' dela" (GOFFMAN, 1959, p.271). Dessa forma, o "eu" enquanto personagem representado é um efeito dramático, não é algo orgânico ou psicobiológico, cujo destino é nascer, crescer e morrer. 
Ao analisar o "eu" é necessário afastar-se de seu possuidor físico, da pessoa que o tem. Ele e seu corpo simplesmente fornecem um suporte, um "cabide no qual algo de uma construção colaborativa será pendurado por algum tempo" (GOFFMAN, 1959, p. 271).

No que se refere ao ator, seus atributos são de natureza psicológica, e não um simples efeito retratado de representações particulares. No entanto, tais atributos parecem surgir da íntima interação com as contingências da representação no palco. O ator é aquele que tem a capacidade de aprender, exercendo esta capacidade na tarefa de treinamento para um papel.

Cortesia e imagem pública - Modelo de BROWN E LEVINSON (1987)

Desde que Brown e Levinson (1987) começaram a fazer parte da literatura pragmalinguística, o conceito de imagem foi tomando espaço primordial na análise da Cortesia verbal. Sua teoria é uma das tentativas mais elaboradas e melhor estruturadas de explicar os motivos e o funcionamento da Cortesia. Este modelo pretende completar o de Grice, acrescentando-lhe o caráter interpessoal de que carecia.

Os autores propõem duas propriedades universais ${ }^{4}$ para interação em sociedade: a noção de autoimagem pública, reelaborada a partir de Goffman (1967), e a noção de racionalidade. Brown e Levinson afirmam que todo indivíduo necessita criar uma imagem própria de si e, também, deseja que esta se

${ }^{4}$ Devido à extensão deste trabalho, direcionaremos nosso foco exclusivamente à noção de imagem pública. torne pública. Sobre esta, cada individuo tem e reclama para si certo prestígio, que quer conservar. Da necessidade de resguardar esta imagem, derivam-se as estratégias de cortesia. A cooperação entre os interlocutores é baseada na suposição compartilhada de que a imagem pública é vulnerável, de que deve ser colocada a salvo e que uma maneira de fazê-lo consiste em não ameaçá-la nem comprometê-la.

Tal imagem é composta por dois aspectos que se relacionam na interação social: a imagem negativa (vontade de preservar e reivindicar seus próprios territórios e sua liberdade de ação) e a imagem positiva (desejo de que sua 'personalidade' e seus 'atos' sejam aprovados e apreciados). Para que nenhum dos aspectos que fazem parte da imagem, tanto do locutor quanto do interlocutor, seja prejudicado é necessário que ambos colaborem para mantê-la em equilíbrio satisfazendo seus desejos de imagem, ou seja, é necessário que façam uso da racionalidade.

É nesse contexto de vulnerabilidade mútua da imagem que qualquer (inter)locutor racional buscará evitar esses atos que a ameaçam, ou empregará estratégias para minimizar uma ameaça. Dentro dessas estratégias, a cortesia negativa está direcionada à imagem negativa do interlocutor, objetiva respeitá-la e satisfazê-la, (quase) não interferindo na liberdade de ação do destinatário. A cortesia positiva se orienta à imagem positiva do interlocutor, procura protegê-la e aceitá-la.

Para conseguir manter essa imagem intacta, o locutor necessita, geralmente, suavizar o potencial ameaçador de seus atos de 
fala e, para tanto, o uso de mecanismos de cortesia torna-se necessário. Essa consideração diz respeito a normas ou convenções das que o locutor pode se desviar incidental ou, inclusive, estruturalmente. Por isso, "la imagen es fundamental en la teoría de la cortesía. Tenemos que entender como tal la proyección social que hacemos de nosotros mismos, que es lo que se pone en juego en la interacción verbal" (RODRÍGUEZ, 2010, p.11). Contudo, isso não significa que a imagem pública do locutor seja uma constante, ela é construída de acordo com seus objetivos em cada situação interativa.

Dessa maneira, podemos afirmar que a cortesia se baseia no fator interativo da comunicação, preocupa-se com o interlocutor, representa uma forma de comportamento regido por princípios de racionalidade. Com frequência, os interlocutores se guiam por esses princípios para prevenir que a relação social entre si tenha seu equilíbrio prejudicado.

Esse caráter inerentemente racional da cortesia será observado, neste trabalho, desde a categoria de interação, que se manifesta por meio das considerações à imagem. Desde essa perspectiva, o locutor desenvolve, guiando-se pela índole específica da situação interativa, estratégias que servem para reforçar a imagem positiva de seu interlocutor ou para prevenir que a imagem negativa do mesmo seja ameaçada. O que importa, neste caso, é manter as relações sociais com o auxilio das expressões de cortesia. Esta será a categoria analisada em nosso corpus. De modo muito simplificado, podemos considerar que a cortesia é uma atividade de relação interpessoal que está orientada em função do interlocutor e que pode ser manifestada e analisada por meio de certos mecanismos de expressão.

\section{CORTESIA: MECANISMOS DE EXPRESSÃO}

Nossa língua possui mecanismos expressivos marcados como corteses ou descorteses. É preciso entender o comportamento e os valores que alguns deles aportam para poder dar sequência a esta investigação, pois, ainda que o contexto inverta seus valores, fica sempre no interlocutor o eco de seu conteúdo básico (RODRÍGUEZ, 2010).

Esses mecanismos se dividem em duas categorias: intensificadores e atenuadores. Os primeiros, em geral, interpretam-se como mecanismos descorteses e os segundos como corteses. Essa classificação desconsidera que somente podemos afirmar que um ato é cortês ou não a partir de seu uso em um determinado contexto.

Os intensificadores potencializam o valor do ato de cortesia ou descortesia. Seus efeitos vão depender do uso que fazemos deles: para enfatizar atos que enaltecem a imagem do interlocutor ou para enfatizar atos que prejudiquem a imagem do mesmo.

Por outro lado, os atenuadores reduzem o valor significativo de um enunciado ou mitigam a força ilocutiva de um ato de fala. Esse efeito de minimização pode ser alcançado através do uso de certos mecanismos linguísticos, como a mudança de modalidade ou força ilocutiva de um ato (atos de fala indiretos) ou ainda, o oferecimento de opções ao interlocutor. Por meio de ambos os mecanismos, fazemos uso de um modo de expressão não impositiva para um ato que o é originariamente. Essas minimizações são 
utilizadas, na maioria das vezes, em um contexto de distância comunicativa entre os interlocutores; um locutor quer ser cortês com seu interlocutor para que colabore consigo ou porque não tem confiança nele.

\section{BASTIDORES DAS ETAPAS: METODOLOGIA}

Conforme o mencionado anteriormente, propomo-nos a examinar, neste trabalho, duas interações presentes na propaganda Surpresa em uma loja VIVO, que faz parte da campanha publicitária \#TAMOCONECTADO de uma operadora brasileira de telefonia móvel e fixa, internet banda larga e TV por assinatura. Nosso objetivo geral é tentar compreender o que leva $\mathrm{L} 2^{5}$, quando questionado por $\mathrm{L} 3^{6}$ acerca de seu ponto de vista sobre a Seleção Brasileira na Copa do Mundo de Futebol 2014, a reformular o exposto anteriormente para $\mathrm{Li}^{7}$.

Para tanto, necessitamos a) apurar quais mecanismos linguísticos são utilizados por L2 nas interações com o L1 e, também, com o L3; b) averiguar em quais interações são utilizadas estratégias de cortesia por parte do L2; e c) analisar de que modo tais mecanismos linguísticos e de sentido se relacionam na materialidade definida para, a partir de tal análise, traçar alguns paralelos, junções e disjunções entre os efeitos de cortesia e a impressão de imagens sociais.

Na próxima seção deste trabalho, mostraremos alguns trechos de transcrição da

\footnotetext{
${ }^{5}$ Ivan - Cliente da VIVO.

${ }^{6}$ Luiz Felipe Scolari (Felipão) - Técnico da Seleção Brasileira de Futebol, 2014.

${ }^{7}$ Funcionário da VIVO.
}

propaganda que nos pareceram mais significativos para alcançar o objetivo proposto. Para cada fragmento, buscaremos verificar os pontos mencionados no parágrafo anterior e analisar o que a materialidade linguística nos permite. $O$ restante da transcrição consta em nossos anexos.

Os métodos de análise utilizados neste trabalho correspondem à articulação entre $o$ de base qualitativa e o de um paradigma indiciário. A adoção de uma metodologia qualitativa cabe neste trabalho devido ao fato de que ela costuma ser direcionada ao longo de sua realização e, além disso, não busca enumerar ou medir eventos (MORESI, 2003).

O paradigma indiciário se caracteriza pela pressuposição de que detalhes, aparentemente negligenciáveis, podem revelar fenômenos densos de notável abrangência. Como, em nosso caso, não podemos reproduzir fielmente os objetivos dos interlocutores ao criarem suas imagens, nem os motivos que levaram cada locutor a fazê-lo, resta-nos inferi-los a partir dos efeitos que a materialidade utilizada ocasiona, por meio da observação de indícios.

Ginzburg (1989), ao se referir às discussões sobre a não-cientificidade da medicina, mostra o que as ciências humanas enfrentariam, posteriormente, em sua epistemologia:

Em primeiro lugar, não bastava catalogar todas as doenças até compô-las num quadro ordenado: em cada indivíduo, a doença assumia características diferentes. Em segundo lugar, o conhecimento das doenças permanecia indireto, indiciário: o corpo vivo era, por definição, inatingível. Certamente podia-se seccionar o cadáver; mas como, 
do cadáver, já corrompido pelos processos da morte, chegar às características do indivíduo vivo? (GINZBURG, 1989, p.166).

Se nessa citação substituirmos o termo doenças por 'palavras' e os termos indivíduo/ corpo/cadáver por 'texto', teremos delineada a situação em que nos encontramos em nossa área de estudos: "atitude orientada para a análise de casos individuais, reconstruíveis somente através de pistas, sintomas, indícios" (GINZBURG, 1989, p.154) e, mais especificamente, através de mecanismos linguísticos.

De acordo com Ginzburg (1989), apenas observando atentamente e registrando com extrema minúcia todas as estratégias linguísticas, seria possível elaborar 'histórias' mais ou menos precisas de cada objetivo: a intenção do locutor seria, em si, inatingível, pois os eventos não são diretamente experimentáveis pelo pesquisador.

Mecanismos Linguísticos X EFeITOS DE SENTIDO: ANÁLISE E DISCUSSÃO

Em razão da Copa do Mundo da FIFA Brasil 2014, a empresa VIVO lançou a ação \#TAMOCONECTADO com a qual propõe a conecção de seus clientes com a Seleção Brasileira $^{8}$. Para a primeira propaganda da campanha, Surpresa em uma Loja Vivo, a empresa optou por gravar as reações ${ }^{9}$ de alguns

\footnotetext{
8 "Você pode receber ligações e mensagens personalizadas dos nossos craques. Cadastre-se para receber mensagens gratuitas exclusivas do Felipão e dos craques David Luiz, Hulk e Bernard durante os jogos" (informação disponível no site da empresa).

${ }^{9}$ Nosso objetivo não é discutir nem analisar se as interações mostradas são espontâneas ou se houve algum tipo
}

clientes, em uma de suas lojas ${ }^{10}$, ao se depararem com a entrada de Luiz Felipe na sala de atendimento premium onde estes clientes se encontravam.

Na propaganda, cada um dos sete $\mathrm{e}^{11}$ (07) clientes mostrados dirige-se à sala de atendimento premium para conversar com o atendente da VIVO. Este lhes pergunta comolhes pode ajudar, ou seja, o motivo que lhes levou até lá e, depois da resposta dos clientes, LI lhes pergunta:

Lı: e o que que cê tá achando da seleção Talita?

LI: cê acredita que ganha?

Um dos clientes, L2, contesta essa pergunta da seguinte forma:

$$
\begin{array}{r}
\text { L2: Eu acho difí::cil... o time é muito } \\
\text { desorganizado -- }
\end{array}
$$

Nesta resposta, L2 faz uso de uma relação consequência-causa: devido ao fato de o time ser muito desorganizada, L2 acha difícil que a seleção ganhe a Copa do Mundo de 2014. O uso do verbo "ser" indica que, de fato, o time possui a característica negativa apontada pelo adjetivo "desorganizado" e intensificada pelo uso do advérbio "muito". Porém, ao empregar o verbo "achar", L2 atenua modalmente a asserção o que, neste caso, indica uma incerteza sobre a total impossibilidade

\footnotetext{
de encenação que forjasse tais reações.

${ }^{10} \mathrm{~A}$ loja referida fica localizada no Shopping Eldorado na cidade de São Paulo. A gravação foi feita no dia 17 de abril de 2014, pelo turno da manhã (informação disponível na própria propaganda Surpresa em uma loja VIVO).

${ }^{11}$ Três mulheres, três homens e um casal.
} 
de alcançar a vitória. Neste momento da interação, Li e L2 possuem a mesma posição hierárquica (P) e não há distância social (D) entre eles, pois, dentro da sequência temática desenvolvida, ambos se colocam como torcedores brasileiros.

Após a resposta de cada cliente, Li lhes informa:

L1: então eu vou te pedir um instantinho que eu vou chamar o técnico TÁ-

O substantivo técnico ${ }^{12}$, de acordo com as acepções elencadas por Houaiss (2001, p. 2683), pode ser empregado com dois significados distintos: especialista em algo ou treinador. No momento de emprego deste substantivo por Li em seu enunciado, o contexto físico $^{13}$ onde os clientes e L1 se encontram imprime uma suposta quebra da sequencia temática do enunciado anterior. Dessa forma, para os clientes da loja, a palavra utilizada adquire o sentido de especialista em telefonia móvel e fixa, internet banda larga e TV por assinatura. Para Li, contudo, não há esta quebra temática, pois emprega o substantivo com o sentido de técnico de futebol.

Após o aviso de L1, este se retira da sala de atendimento e o técnico, Luis Felipe Scolari (L3), entra em cena e inicia suas interações com os clientes:

L3: bom dia... queria falar comigo?

\footnotetext{
12 "técnico [...] s.m. 4 (1881) aquele que é versado numa arte ou ciência; especialista, perito, experto $<0$ parecer de $u m$ t.> 5 DESP profissional encarregado de treinar e orientar taticamente um conjunto esportivo; treinador $<$ t. de futebol $><0$ novo t. da seleção de vôlei $>$ [...]" (HOUAISS, 2001, p.2683).

${ }^{13}$ Loja da VIVO.
}

L2: oi bom dia... tudo bom? O:::::: Felipão tudo bem? ((ficou com o rosto vermelho))

Quando os clientes percebem quem é L3, há, para eles, uma nova quebra de sequencia temática, pois esperavam falar com o especialista em telefonia móvel e fixa, internet banda larga e TV por assinatura e não com o treinador de futebol.

L3 lhes faz uma mesma pergunta realizada anteriormente por Li:

L3: que tu acha da nossa seleÇÃO?

Em virtude da mudança de interlocutor, interação entre L2 e L3, aquele sente necessidade de modalizar sua resposta:

L3: eu acho que assim ... muito pouco tem::po pro time jogar junto, então acho que ...acaba ficando meio desorganiza::do o time às vezes taticamente fala::ndo

Comparada à resposta dada a L1, esta última é mais extensa, pois L2 emprega vários atenuadores em sua asserção. Enquanto para Li utiliza-se o verbo "ser", para L3 usa-se "achar" que, neste caso, introduz uma perspectiva particular, uma possibilidade, o modo como L2 vê a seleção, e, acaba atenuando a asserção modalmente. $O$ uso de “assim”, que faz o interlocutor esperar por uma expressão vindoura, é considerado um retardatário que também atenua o dito.

Com "muito pouco tem::po pro time jogar junto", L2 serve-se, também, do uso de um procedimento discursivo que atua como atenuador do ato: a justificativa. Ele oferece um argumento que apresenta o que 
diz como uma conclusão de algo (reforçada pelo uso da conjunção conclusiva "então"), ainda que não o deseje: "acaba ficando meio desorganiza::do o time às vezes taticamente fala::ndo".

Em sua conclusão, ao contrário do intensificador "muito" utilizado na resposta para L1, L2 aplica o adjetivo "meio", com sentido de "um pouco", que indica a minimização da quantidade ou a pequena quantidade de desorganização; a locução adverbial temporal "às vezes", que implica que a pequena desorganização ocorre esporadicamente; e, no final, restringe a desorganização, somente, à questão tática. Todas estas estratégias servem como atenuadoras de atos potencialmente ameaçadores à L3.

Tendo ouvido os pontos de vista dos clientes sobre a Seleção Brasileira, a propaganda se encaminha para o final: L3 lhes pergunta se têm alguma sugestão para lhe fazer, ouve-os e fala sobre a ação \#TAMOCONECTADO.

$\mathrm{Na}$ interação entre L2 e L3, sua relação hierárquica é verticalizada e há distância social entre eles, pois, dentro da sequência temática desenvolvida, enquanto L3 cumpre a função de técnico da Seleção Brasileira, pessoa famosa a quem é atribuído o poder de decisão sobre os componentes a e forma de atuação da equipe, L2 é somente mais um dos milhões de torcedores brasileiros que expressam palpites sobre o time.

Como atividade social, a cortesia é um fenômeno de aproximação ao outro, é uma das principais atividades sociais que colaboram para o sucesso de uma interação comunicativa. É um código de conduta das relações sociais que, de acordo com as culturas e as situações, regula o tratamento adequado entre as pessoas e se facilita a vida social ao projetar-se na atividade comunicativa (MARCO y GARCÍA, 2013, p.5).

Como apontam Brown e Levinson (1978), tais variáveis sociológicas interferem na escolha das estratégias de compensação do grau de ameaça à imagem, como a distância social e hierárquica entre os interlocutores, e são esses os motivos que levam L2 a modificar suas respostas à mesma pergunta para interlocutores diferentes.

A expressão de uma opinião, muitas vezes, pode ser considerada impositiva para o interlocutor, por isso, a atenuação de um ato que este possa considerar invasivo é um dos mecanismos fundamentais para a cortesia (RODRÍGUEZ, 2010). Para não invadir o território de L3 de modo descortês, L2 utiliza-se de recursos linguísticos, de estratégias de atenuação que buscam minimizar os efeitos negativos de uma possível ameaça tanto à imagem positiva (no que se refere à Seleção Brasileira de Futebol, desejo que as pessoas aceitem e confiem em suas escolhas) e à imagem negativa (também no que se refere à Seleção Brasileira de Futebol, necessidade de manter a sua função e o seu poder enquanto técnico) de L3 quanto às suas próprias imagens positiva (sua opinião sobre a equipe ser aceita) e negativa (assegurar sua parcela de importância enquanto torcedor), mantendo a interação em equilíbrio para ambos.

Podemos perceber que, frente a $\mathrm{LI}$, ao ser mais direto, não fazendo uso de tantas atenuações, L2 tenta projetar uma imagem de torcedor consciente das limitações da 
Seleção Brasileira. L2 não extingue a possibilidade de vitória, mas, em sua opinião, isso vai ser complicado, difícil. Conforme afirmamos anteriormente, não há uma relação de hierarquia ou de distância social entre Li e L2 no que se refere à temática da Copa do Mundo de Futebol FIFA Brasil 2014, sua relação é simétrica, pois ambos se encontram no mesmo papel, o de torcedores.

Entretanto, na interação com L3, a relação hierárquica e a distância social mudam drasticamente. E é isso que faz com que L2 modifique sua resposta. Não falamos mais em dois torcedores, mas em um torcedor e o técnico. Ao manifestar sua opinião de leigo a um especialista em futebol afamado, L2 sente a necessidade de diminuir o efeito descortês de sua asserção. Utiliza mecanismos que atenuam a imposição de sua opinião e, dessa maneira, provoca uma impressão de cortesia ao não atacar de modo explícito as imagens de L3.

Seguindo o proposto por Goffman (1959), poderíamos sustentar que Ivan seria o "cabide" para as duas imagens distintas esboçadas, uma imagem face a face com Li e outra imagem face a face com L3 e que Luiz Felipe Scolari seria o "cabide" para a personagem, para a impressão da imagem de técnico, L3. Da necessidade de resguardar estas imagens, no caso específico deste trabalho, derivam-se as estratégias atenuação com a finalidade de provocar efeitos de cortesia. É nesse contexto de vulnerabilidade mútua da imagem que qualquer (inter)locutor racional buscará evitar esses atos que a ameaçam, ou empregará estratégias para minimizar uma ameaça.

\section{Possibilidades DE CHeGada: CONSIDERAÇÕES FINAIS}

Cada língua é acompanhada por costumes específicos que dependem das rotinas de uma determinada sociedade. Para conhecer um grupo social, ou reconhecer-se como parte dele é preciso conhecer seus tipos de comportamento, sobretudo, os referentes à linguagem. Em certas circunstâncias, para conseguir um fim argumentativo preestabelecido: a colaboração do interlocutor, sua disposição para lê-lo ou ouvi-lo, para entendê-lo e para admitir manifestações pessoais ou ataques a sua imagem, o locutor faz uso de alguns elementos de cortesia estratégica. Em outras, existem rotinas preestabelecidas, de modo que a realização de um ato de fala depende do emprego de algumas estruturas de cortesia ritual convencionalmente aceitas, tais como: cumprimentos, agradecimentos, felicitações, elogios, etc.

Havendo necessidade de estabelecer algum tipo de interação interpessoal, o indivíduo pode optar por fazer uso ou não desses mecanismos que demonstrem apreço e respeito pelo outro. Quando o L2 tem em conta o seu interlocutor, L3, e a imagem que projeta tem a finalidade de não desfazer a interação, de assegurá-la, referimo-nos a atividades de cortesia.

A asserção, em si, pode consistir em proporcionar dados e informações e, neste sentido, somos colaborativos, corteses. Contudo, quando estas informações pertencem ao campo do opinável, como no caso da resposta de $\mathrm{L} 2$ à pergunta de $\mathrm{L} 3$, o aconselhado é atenuá-las, para não parecerem impositivas (RODRÍGUEZ, 2010). Expressar 
uma valoração de modo direto supõe um ato comprometido que pode ser interpretado como um ataque à imagem e isto se torna mais forte quanto mais distante seja a relação entre os interlocutores. Portanto, uma asserção atenuada se transforma em um ato mais cortês que afirmar, que opinar de forma categórica.

Por meio deste trabalho, foi possível perceber que, ao utilizar uma língua, da mesma forma que seguimos regras semânticas e sintáticas, seguimos, também, regras pragmáticas. Todas essas normas devem fazer parte de nossas regras linguísticas.

As estratégias de cortesia existem; os locutores as usam de modo sistemático para garantir ou modificar o estatuto de suas relações sociais, para melhorar o tratamento amistoso, estabelecer um ambiente de respeito mútuo ou, inclusive, para se distanciar do interlocutor. Todas estas regras devem fazer parte de nosso uso consciente de uma língua visto que não são mecanismos de uso meramente linguístico, mas podem ser aplicados também a todas as transações humanas cooperativas.

\section{REFERÊNCIAS}

BRAVO, D.; BRIZ, A. (eds.). Pragmática Sociocultural: estudios sobre el discurso de cortesía en español. Barcelona: Ariel Editorial, 2004.

BROW, P.; LEVINSON, S. Some universals in language usage. Cambridge: Cambridge University Press, 1987.

GINZBURG, C. Mitos, emblemas, sinais: morfologia e história. São Paulo: Companhia das Letras, 1989.
GOFFMAN, Erving (1959). A representação do eu na vida cotidiana. Petrópolis, RJ: Editora Vozes, 2013.

. (1967). Ritual de Interação: ensaios sobre o comportamento face a face. Tradução: Fábio Rodrigues Ribeiro da silva. São Paulo: Editora Vozes, 2011.

HAVEKATE, H. La cortesía verbal: estudio pragmalingüístico. Madrid: Editorial Gredos, 1994.

HOUAISS, A.; VILLAR, M. S. Dicionário Houaiss da Língua Portuguesa. Rio de Janeiro: Objetiva, 2001.

MARCO, M. A.; GARCÍA, M. J. B. La cortesía en la comunicación. Madri: Arco Libros, 2013.

MORESI, E. (org.). Metodologia da Pesquisa. Programa de pós-graduação stricto sensu em gestão do conhecimento e tecnologia da informação: UCB, 2003.

RODRÍGUEZ, C. F. La gramática de la Cortesía en español/LE. Madrid: Arco Libros S.A.: 2010. SITE DA VIVO. Eu vivo Esporte \#TAMOCONECTADO. Disponível em: <https:// www.euvivoesporte.com.br/tamoconectado? gclid=CO3DjIaKhb8CFWMQ7AodDAcAvg $>$ Acesso em: 20 jun. 2014.

VIDAL, M. V. E. Introducción a la pragmática. Barcelona: Editorial Ariel S.A., 1999.

Aportaciones de la Pragmática. Departamento de Lengua Española y Lingüística General: UNED s/d. Disponível em: http://www.textosenlinea.com.ar/textos/ Aportaciones\%2ode\%2ola\%2opragmatica.pdf Acesso em: 24 jun. 2014.

Recebido para publicação em 08 nov. 2015. Aceito para publicação em 25 ago. 2016. 
Anexos

Transcrição-03mino7seg até $05 \mathrm{~min} 59 \mathrm{seg}$

\#TAMOCONECTADO - Surpresa em uma

\section{Loja Vivo}

Shopping Eldorado - SP

17 de Abril de 2014

10:15

\section{$[\ldots]$}

LI: senha dezenove.

[...]

Li: como que eu posso ajudar ivan?

Cliente: Eu:::: queria mudar de pla::no --

\section{[...]}

LI: e o que que cê tá achando da seleção

Talita?

$$
\text { [...] }
$$

LI: cê acredita que ganha?

L2: Eu acho difí::cil... o time é muito desor-

ganizado --

\section{[...]}

L1: então eu vou te pedir um instantinho que eu vou chamar o técnico TÁ --

\section{[...]}

L3: bom dia... queria falar comigo?

L2: oi bom dia... tudo bom? O::::::: Felipão tudo

bem? ((ficou com o rosto vermelho))

\section{[...]}

L3: que tu acha da nossa seleÇÃO?

L2: eu acho que assim ... muito pouco tem::po

pro time jogar junto, então acho que ...acaba

ficando meio desorganiza::do o time às vezes

taticamente fala::ndo

L3: alguma sugestão?

L2: pudia levar o Ivan para a seleção NÉ
L1: Atendente da Vivo

L2: Cliente (Ivan)

L3: Luiz Felipe Scolaria (Felipão - Técnico da

Seleção Brasileira 2014)

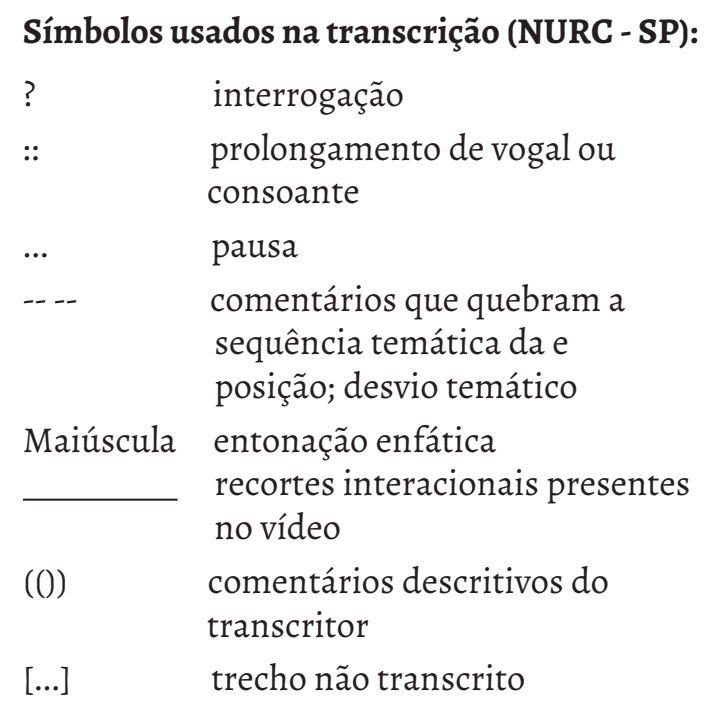

